Прилози, Одд. мат. тех. науки, МАНУ, XXVII-XXVIII, 1-2 (2006-2007), стр. 41-53 Contributions, Sec. Math. Tech. Sci., MANU, XXVII-XXVIII, 1-2 (2006-2007), pp. 41-53

\title{
QUASIGROUP STRING PROCESSING: PART 4
}

\author{
Smile Markovski and Verica Bakeva
}

\begin{abstract}
A b s t r a c t: Given a finite alphabet $A$ and a quasigroup operation $*$ on the set $A$, in earlier paper of ours we have defined the quasigroup transformation $E: A^{+} \rightarrow A^{+}$, where $A^{+}$is the set of all finite strings with letters from $A$. Here we present several generalizations of the transformation $E$ and we consider the conditions under which the transformed strings have uniform distributions of $n$-tuples of letters of $A$. The obtained results can be applied in cryptography, coding theory, defining and improving pseudo random generators, and so on.
\end{abstract}

Key words: quasigroup, quasigroup string processing, uniform distribution

AMS Mathematics Subject Classification (2000): 20N05, $60 \mathrm{E} 05$

\section{PRELIMINARIES}

The quasigroup string transformations $E$ and $D$, and their properties, were considered in several papers ([3], [4], [5], [6], [7]). Here we give generalizations of the transformation $E$ and we investigate conditions under which the string obtained by such generalized transformations have uniform distributions of $n$-tuples of letters. The needed definitions used in this paper can be found in the above-cited papers and in [1], [2]. Here we give some of them for matter of completeness.

A quasigroup $(Q, *)$ is a groupoid (i.e. algebra with one binary operation $*$ on the set $Q$ ) satisfying the law:

$$
(\forall u, v \in Q)(\exists ! x, y \in Q) \quad(x * u=v \& u * y=v)
$$


In fact, $(1)$ says that a groupoid $(Q, *)$ is a quasigroup if and only if the equations $x * u=v$ and $u * y=v$ have unique solutions $x$ and $y$ for each given $u, v \in Q$. It is usual the solutions $x$ and $y$ to be denoted by $x=v / u$ and $y=u \backslash v$. In such a way two new operations / (a right division) and $\backslash$ (a left division) are defined on the set $Q$, and then also $(Q, /)$ and $(Q, \backslash)$ are quasigroups.

We define a quasigroup string transformation $E$ as follows.

Let $A=\{1, \ldots, s\}$ be an alphabet $(s \geq 2)$ and denote by $A^{+}=$ $\left\{x_{1} \ldots x_{k} \mid \quad x_{i} \in A, k \geq 1\right\}$ the set of all finite strings over $A$. Note that $A^{+}=\bigcup\left(A^{k} \mid k \geq 1\right)$, where $A^{k}=\left\{x_{1} \ldots x_{k} \mid x_{i} \in A\right\}$. Let $*$ be a quasigroup operation on the set $A$ and take a fixed element $l \in A$, called a leader. Define a transformation $E=E_{l, *}: A^{+} \rightarrow A^{+}$as follows.

$$
E\left(x_{1} \ldots x_{k}\right)=y_{1} \ldots y_{k} \Longleftrightarrow\left\{\begin{aligned}
y_{1} & =l * x_{1}, \\
y_{i+1} & =y_{i} * x_{i+1}, \quad i=1, \ldots, k-1,
\end{aligned}\right.
$$

where $x_{i}, y_{i} \in A$. We say that the string $x_{1} \ldots x_{k}$ is an input message, while $y_{1} \ldots y_{k}$ is the output message of $E$.

Using the transformation $E$, in Section 2 we prove that an input message with uniformly distributed $n$-tuples of letters is transformed to output message with uniformly distributed $n+1$-tuples of letters. So, starting with an input message where the distribution of the letters is uniform, after one application of an E-transformation an output message with uniformly distributed pairs of letters will be obtained. Applying again an $E$-transformation on the output, the new output will have uniformly distributed triplets of letters. That way, after $n$ applications of the $E$ transformation, we can obtain a message with uniformly distributed $n+1$ tuples of letters. By using Markov chains it was shown in the paper [4] that, after applying an $E$-transformation on arbitrary input message, an output message with uniformly distributed letters is obtained.

Generalizations of the transformation $E$ are given in Section 3. It is shown that for the generalized transformations the following holds: if an input message has uniformly distributed $n$-tuples of letters, then the output message has uniformly distributed $n+d$-tuples of letters for $1 \leq d \leq n$. We made several experiments that support our results, and they are presented in Section 4. Possible applications of our results are discussed in Section 5. 


\section{UNIFORMITY OBTAINED BY E-TRANSFORMATION}

Let the alphabet $A$ be as above. A randomly chosen element of the set $A^{k}$ can be considered as a random vector $\left(X_{1}, X_{2}, \ldots, X_{k}\right)$, where $A$ is the range of $X_{i}, i=1, \ldots, k$. We consider these vectors as input messages. The transformation $E=E_{l, *}: A^{+} \rightarrow A^{+}$can be applied on random vectors as

$$
E\left(X_{1} \ldots X_{k}\right)=Y_{1} \ldots Y_{k} \Longleftrightarrow\left\{\begin{aligned}
Y_{1} & =l * X_{1}, \\
Y_{i+1} & =Y_{i} * X_{i+1}, \quad(i=1, \ldots, k-1)
\end{aligned}\right.
$$

Let $\left(X_{1}, X_{2}, \ldots, X_{\alpha}\right)$ be an input message such that, for any fixed $1 \leq n \leq \alpha$ and for each $0 \leq t \leq \alpha-n$, the vectors $\left(X_{t+1}, X_{t+2}, \ldots, X_{t+n}\right)$ are uniformly distributed on the set $\{1,2, \ldots, s\}^{n}$, i.e.

$$
\left(X_{t+1}, X_{t+2}, \ldots, X_{t+n}\right) \sim U\left(\{1,2, \ldots, s\}^{n}\right)
$$

in other words, let the $n$-tuples in the input messages be uniformly distributed. As a consequence, note that $k$-tuples of the input messages will be also uniformly distributed for each $k \leq n$, i.e. $\left(X_{t+1}, X_{t+2}, \ldots\right.$ $\left.\ldots, X_{t+k}\right) \sim U\left(\{1,2, \ldots, s\}^{k}\right), t=0,1, \ldots$. Hence, for $k=1$ we have that $X_{t+1} \sim U(\{1,2, \ldots, s\})$, for each $t \geq 0$, i.e., the letters are uniformly distributed too.

Let $\left(Y_{1}, Y_{2}, \ldots, Y_{\alpha}\right)$ be a random vector obtained from the vector $\left(X_{1}, X_{2}, \ldots, X_{\alpha}\right)$ by an $E$-transformation of kind (3). According to the definition of (3), $Y_{t}$ is independent of the random variables $X_{t+1}, X_{t+2}, \ldots$, for each $t \geq 1$.

Proposition $1 \quad Y_{t} \sim U(\{1,2, \ldots, s\})$ for each $t \geq 1$.

Proof For $t=1, X_{1} \sim U(\{1,2, \ldots, s\})$ implies

$$
P\left\{Y_{1}=i\right\}=P\left\{l * X_{1}=i\right\}=P\left\{X_{1}=l \backslash i\right\}=\frac{1}{s}, \quad i=1,2, \ldots, s .
$$

This means that $Y_{1} \sim U(\{1,2, \ldots, s\})$. We proceed by induction, and let suppose that $Y_{r} \sim U(\{1,2, \ldots, s\})$. Using the equations (3), total probability theorem and the independence of $Y_{r}$ and $X_{r+1}$ we compute the distribution of $Y_{r+1}$ as follows.

Прилози, Одд. мат. тех. науки, XXVII-XXVIII, 1-2 (2006-2007), стр. 41-53 


$$
\begin{aligned}
P\left\{Y_{r+1}=i\right\} & =P\left\{Y_{r} * X_{r+1}=i\right\}=\sum_{k=1}^{s} P\left\{Y_{r} * X_{r+1}=i, Y_{r}=k\right\} \\
& =\sum_{k=1}^{s} P\left\{k * X_{r+1}=i, Y_{r}=k\right\}=\sum_{k=1}^{s} P\left\{X_{r+1}=k \backslash i, Y_{r}=k\right\} \\
& =\sum_{k=1}^{s} P\left\{X_{r+1}=k \backslash i\right\} P\left\{Y_{r}=k\right\}=\sum_{k=1}^{s} \frac{1}{s} \cdot \frac{1}{s}=\frac{1}{s},
\end{aligned}
$$

for $i=1,2, \ldots, s$.

The Proposition 1 can be generalized as follows.

Theorem 1 Let $\left(X_{1}, X_{2}, \ldots, X_{\alpha}\right)$ be a given random vector such that $\left(X_{t+1}, X_{t+2}, \ldots, X_{t+n}\right) \sim U\left(\{1,2, \ldots, s\}^{n}\right)$ for each $t \geq 0$ and for fixed $n \geq$ 1. If $\left(Y_{1}, Y_{2}, \ldots, Y_{\alpha}\right)$ is a random vector obtained by $E$-transformation of the vector $\left(X_{1}, X_{2}, \ldots, X_{\alpha}\right)$, then $\left(Y_{t+1}, Y_{t+2}, \ldots, Y_{t+m}\right) \sim U\left(\{1,2, \ldots, s\}^{m}\right)$ for each $m \leq n+1$ and each $t \geq 0$.

Proof Let $m \leq n+1$ be a fixed positive integer. We will find the distribution of the vector $\left(Y_{t+1}, Y_{t+2}, \ldots, Y_{t+m}\right)$ for arbitrary $t$.

$$
\begin{aligned}
& P\left\{Y_{t+1}=y_{t+1}, Y_{t+2}=y_{t+2}, \ldots, Y_{t+m}=y_{t+m}\right\} \\
& \quad=P\left\{Y_{t+1}=y_{t+1}, Y_{t+1} * X_{t+2}=y_{t+2}, \ldots, Y_{t+m-1} * X_{t+m}=y_{t+m}\right\} \\
& \quad=P\left\{Y_{t+1}=y_{t+1}, y_{t+1} * X_{t+2}=y_{t+2}, \ldots, y_{t+m-1} * X_{t+m}=y_{t+m}\right\} \\
& \quad=P\left\{Y_{t+1}=y_{t+1}, X_{t+2}=y_{t+1} \backslash y_{t+2}, \ldots, X_{t+m}=y_{t+m-1} \backslash y_{t+m}\right\} \\
& \quad=P\left\{Y_{t+1}=y_{t+1}\right\} P\left\{X_{t+2}=y_{t+1} \backslash y_{t+2}, \ldots, X_{t+m}=y_{t+m-1} \backslash y_{t+m}\right\} .
\end{aligned}
$$

The last equality is obtained by using that $Y_{t+1}$ is independent of the vector $\left(X_{t+2}, \ldots, X_{t+m}\right)$. Since $m \leq n+1$, the vector $\left(X_{t+2}, \ldots, X_{t+m}\right)$ is uniformly distributed to the set $\{1,2, \ldots, s\}^{m-1}$. Applying this to the previous expression, we obtain that

$$
P\left\{Y_{t+1}=y_{t+1}, Y_{t+2}=y_{t+2}, \ldots, Y_{t+m}=y_{t+m}\right\}=\frac{1}{s} \cdot \frac{1}{s^{m-1}}=\frac{1}{s^{m}} .
$$

This means that for each $m \leq n+1$, the vectors $\left(Y_{t+1}, Y_{t+2}, \ldots, Y_{t+m}\right)$ have uniform distribution on the set $\{1,2, \ldots, s\}^{m}$.

Remark 1 Note that for $m>n+1$ the distribution of the vector $\left(X_{t+2}, \ldots\right.$ $\left.\ldots, X_{t+m}\right)$ is not known, so we cannot determine exactly the distribution of the random vector $\left(Y_{t+1}, Y_{t+2}, \ldots, Y_{t+m}\right)$ (which generally is not uniform). We will discuss in Section 3 about the upper bounds of the distribution of the random vector $\left(Y_{t+1}, Y_{t+2}, \ldots, Y_{t+m}\right)$. 
Remark 2 Let consider the transformation $E_{1}: A^{+} \rightarrow A^{+}$defined by

$$
E_{1}\left(X_{1} \ldots X_{k}\right)=Y_{1} \ldots Y_{k} \Longleftrightarrow\left\{\begin{aligned}
Y_{1} & =X_{1} * l, \\
Y_{i+1} & =X_{i+1} * Y_{i}, \quad(i=1, \ldots, k-1)
\end{aligned}\right.
$$

In the same way as Theorem 1 we can prove Theorem $1^{\prime}$, where the transformation $E$ is replaced by the transformation $E_{1}$.

\section{GENERALIZED E-TRANSFORMATIONS}

The transformation $E$ defined in (3) is not the only one that can be used as quasigroup string transformation. Here we will consider some other kind of transformations that generalize the transformation $E$. We will show that they give uniform distribution of higher level than $E$. Namely, we define a transformation $G_{d}$ with following property: after applying $G_{d}$ on an input string with uniformly distributed $n$-tuples we obtain an output string with uniform distribution of $n+d$-tuples, where $d \leq n$.

Let $A$ be as before and let define the transformation $G=G_{d}$ : $A^{+} \rightarrow A^{+}$as follows. Take fixed leaders $l_{1}, l_{2}, \ldots, l_{d} \in A$, where $d$ is a positive integer. Then:

$$
\begin{aligned}
& G\left(X_{1} \ldots X_{k}\right)=Y_{1} \ldots Y_{k} \Longleftrightarrow \\
& \qquad \begin{cases}Y_{1}=l_{1} *\left(l_{2} *\left(\cdots *\left(l_{d-1} *\left(l_{d} * X_{1}\right)\right) \ldots\right)\right) \\
Y_{2}=l_{2} *\left(l_{3} *\left(\cdots *\left(l_{d} *\left(Y_{1} * X_{2}\right)\right) \ldots\right)\right) \\
\ldots \\
Y_{d}=l_{d} *\left(Y_{1} *\left(\cdots *\left(Y_{d-2} *\left(Y_{d-1} * X_{d}\right)\right) \ldots\right)\right) \\
Y_{d+1}=Y_{1} *\left(Y_{2} *\left(\cdots *\left(Y_{d} * X_{d+1}\right) \ldots\right)\right) \\
\ldots \\
Y_{k}= & Y_{k-d} *\left(Y_{k-d+1} *\left(\cdots *\left(Y_{k-1} * X_{k}\right) \ldots\right)\right)\end{cases}
\end{aligned}
$$

Proposition 2 Let $d \leq n$ and $\left(X_{t+1}, X_{t+2}, \ldots, X_{t+n}\right) \sim U\left(\{1,2, \ldots, s\}^{n}\right)$. Then $\left(Y_{t+1}, Y_{t+2}, \ldots, Y_{t+d}\right) \sim U\left(\{1,2, \ldots, s\}^{d}\right)$, for arbitrary $t \geq 0$. 
Proof The distribution of the vector $\left(Y_{t+1}, Y_{t+2}, \ldots, Y_{t+d}\right)$ for $t=0$ is the following.

$$
\begin{aligned}
& P\left\{Y_{1}=y_{1}, \ldots, Y_{d}=y_{d}\right\} \\
& \quad=P\left\{l_{1} *\left(\cdots *\left(l_{d} * X_{1}\right) \ldots\right)=y_{1}, \ldots, l_{d} *\left(Y_{1} *\left(\cdots *\left(Y_{d-1} * X_{d}\right) \ldots\right)\right)=y_{d}\right\} \\
& \quad=P\left\{l_{1} *\left(\cdots *\left(l_{d} * X_{1}\right) \ldots\right)=y_{1}, \ldots, l_{d} *\left(y_{1} *\left(\cdots *\left(y_{d-1} * X_{d}\right) \ldots\right)\right)=y_{d}\right\} \\
& \quad=P\left\{X_{1}=x_{1}, \ldots, X_{d}=x_{d}\right\} \\
& \quad=\frac{1}{s^{d}}
\end{aligned}
$$

where $x_{1}$ is the solution of the quasigroup equation $l_{1} *\left(\cdots *\left(l_{d-1} *\left(l_{d} *\right.\right.\right.$ $x))))=y_{1}$, i.e. $x_{1}=l_{d} \backslash\left(l_{d-1} \backslash\left(\cdots \backslash\left(l_{1} \backslash y_{1}\right)\right)\right)$, and so on, $x_{d}=y_{d-1} \backslash$ $\left(y_{d-2} \backslash\left(\cdots \backslash\left(y_{1} \backslash\left(l_{d} \backslash y_{d}\right)\right)\right)\right)$.

We proceed by induction. Suppose that

$$
\left(Y_{t+1}, \ldots, Y_{t+d}\right) \sim U\left(\{1,2, \ldots, s\}^{d}\right)
$$

for each $t \leq r-1$. Now, the distribution of the vector $\left(Y_{r+1}, \ldots, \ldots, Y_{r+d}\right)$ is the following.

$$
\begin{aligned}
& P\left\{Y_{r+1}=y_{r+1}, \ldots, Y_{r+d}=y_{r+d}\right\} \\
& =P\left\{Y_{r-d+1} *\left(\ldots *\left(Y_{r} * X_{r+1}\right) \ldots\right)=y_{r+1}, \ldots\right. \\
& \left.\ldots, Y_{r} *\left(\cdots *\left(Y_{r+d-1} * X_{r+d}\right) \ldots\right)=y_{r+d}\right\} \\
& =\sum_{k_{1}, \ldots, k_{d}=1}^{s} P\left\{Y_{r-d+1} *\left(\cdots *\left(Y_{r} * X_{r+1}\right) \ldots\right)=y_{r+1}, \ldots\right. \\
& \left.\ldots, Y_{r} *\left(\cdots *\left(Y_{r+d-1} * X_{r+d}\right) \ldots\right)=y_{r+d}, Y_{r-d+1}=k_{1}, \ldots, Y_{r}=k_{d}\right\} \\
& =\sum_{k_{1}, \ldots, k_{d}=1}^{s} P\left\{k_{1} *\left(\cdots *\left(k_{d} * X_{r+1}\right) \ldots\right)=y_{r+1}, \ldots\right. \\
& \left.\ldots, k_{d} *\left(y_{r+1} *\left(\ldots *\left(y_{r+d-1} * X_{r+d}\right) \ldots\right)\right)=y_{r+d}, Y_{r-d+1}=k_{1}, \ldots, Y_{r}=k_{d}\right\} \\
& =\sum_{k_{1}, \ldots, k_{d}=1}^{s} P\left\{X_{r+1}=x_{r+1}, \ldots, X_{r+d}=x_{r+d}, Y_{r-d+1}=k_{1}, \ldots, Y_{r}=k_{d}\right\}
\end{aligned}
$$

where $x_{j}$ are the solutions of the corresponding quasigroup equations. 
Note that the vectors $\left(X_{r+1}, \ldots, X_{r+d}\right)$ and $\left(Y_{r-d+1}, \ldots, Y_{r}\right)$ are independent; namely, by the definition (5) of the transformation $G$ we have that the random variable $Y_{i}$ depends only on the random variables $X_{1}, \ldots, X_{i}$. Therefore, we have

$$
\begin{aligned}
& P\left\{Y_{r+1}=y_{r+1}, \ldots, Y_{r+d}=y_{r+d}\right\} \\
& \quad=\sum_{k_{1}, \ldots, k_{d}=1}^{s} P\left\{X_{r+1}=x_{r+1}, \ldots, X_{r+d}=x_{r+d}\right\} P\left\{Y_{r-d+1}=k_{1}, \ldots, Y_{r}=k_{d}\right\} \\
& \quad=\sum_{k_{1}, \ldots, k_{d}=1}^{s} \frac{1}{s^{d}} \cdot \frac{1}{s^{d}}=\frac{1}{s^{d}}
\end{aligned}
$$

which means that $\left(Y_{t+1}, Y_{t+2}, \ldots, Y_{t+d}\right) \sim U\left(\{1,2, \ldots, s\}^{d}\right)$.

Theorem 2 Let $\left(X_{1}, X_{2}, \ldots, X_{\alpha}\right)$ be a given random vector such that $\left(X_{t+1}, X_{t+2}, \ldots, X_{t+n}\right) \sim U\left(\{1,2, \ldots, s\}^{n}\right)$ for each $t \geq 0$ and for fixed $n \geq$ 1. If $\left(Y_{1}, Y_{2}, \ldots, Y_{\alpha}\right)$ is a random vector obtained by $G_{d}$-transformation of the vector $\left(X_{1}, X_{2}, \ldots, X_{\alpha}\right)$, then $\left(Y_{t+1}, Y_{t+2}, \ldots, Y_{t+m}\right) \sim U\left(\{1,2, \ldots, s\}^{m}\right)$ for each $m \leq n+d$ and each $t \geq 0$.

Proof The theorem is true for $m \leq d$ by Proposition 2. Let fix an integer $m, d<m \leq n+d$. We find the distribution of the vector $\left(Y_{t+1}, Y_{t+2}, \ldots, Y_{t+m}\right)$, for arbitrary $t$, as follows.

$$
\begin{gathered}
P\left\{Y_{t+1}=y_{t+1}, \ldots, Y_{t+d}=y_{t+d}, Y_{t+d+1}=y_{t+d+1}, \ldots, Y_{t+m}=y_{t+m}\right\} \\
=P\left\{Y_{t+1}=y_{t+1}, \ldots, Y_{t+d}=y_{t+d}, Y_{t+1} *\left(\cdots *\left(Y_{t+d} * X_{t+d+1}\right) \ldots\right)=y_{t+d+1}, \ldots\right. \\
\left.\ldots, Y_{t+m-d} *\left(\cdots *\left(Y_{t+m-1} * X_{t+m}\right) \ldots\right)=y_{t+m}\right\} \\
=P\left\{Y_{t+1}=y_{t+1}, \ldots, Y_{t+d}=y_{t+d}, y_{t+1} *\left(\cdots *\left(y_{t+d} * X_{t+d+1}\right) \ldots\right)=y_{t+d+1}, \ldots\right. \\
\left.\ldots, y_{t+m-d} *\left(\cdots *\left(y_{t+m-1} * X_{t+m}\right) \ldots\right)=y_{t+m}\right\} \\
=P\left\{Y_{t+1}=y_{t+1}, \ldots, Y_{t+d}=y_{t+d}, X_{t+d+1}=x_{t+d+1}, \ldots, X_{t+m}=x_{t+m}\right\}
\end{gathered}
$$

where $x_{i}$ are the solutions of the corresponding quasigroup equations (i.e. $x_{t+d+1}=y_{t+d} \backslash\left(y_{t+d-1} \backslash\left(\cdots \backslash\left(y_{t+1} \backslash y_{t+d+1}\right) \ldots\right)\right)$, and so on. $)$ pendent, we have

Since the vectors $\left(X_{t+d+1}, \ldots, X_{t+m}\right)$ and $\left(Y_{t+1}, \ldots, Y_{t+d}\right)$ are inde-

$$
\begin{aligned}
& P\left\{Y_{t+1}=y_{t+1}, \ldots, Y_{t+m}=y_{t+m}\right\} \\
& \quad=P\left\{Y_{t+1}=y_{t+1}, \ldots, Y_{t+d}=y_{t+d}\right\} P\left\{X_{t+d+1}=x_{t+d+1}, \ldots, X_{t+m}=x_{t+m}\right\} .
\end{aligned}
$$

Прилози, Одд. мат. тех. науки, XXVII-XXVIII, 1-2 (2006-2007), стр. 41-53 
Now, since $m-d \leq n$, the vector $\left(X_{t+d+1}, \ldots, X_{t+m}\right)$ is uniformly distributed on the set $\{1,2, \ldots, s\}^{m-d}$. Then, by Proposition 2, we have

$$
P\left\{Y_{t+1}=y_{t+1}, \ldots, Y_{t+m}=y_{t+m}\right\}=\frac{1}{s^{d}} \cdot \frac{1}{s^{m-d}}=\frac{1}{s^{m}} .
$$

The distributions of the vectors $\left(Y_{t+1}, \ldots, Y_{t+m}\right)$ must not be uniform in the case $m>n+d$. By the next theorem, it can be seen that the distribution of the $m$-tuples is becoming closer to the uniform distribution with increasing of $d(d<m-n)$.

Theorem 3 Let $\left(X_{1}, X_{2}, \ldots, X_{\alpha}\right)$ be a given random vector such that $\left(X_{t+1}, X_{t+2}, \ldots, X_{t+n}\right) \sim U\left(\{1,2, \ldots, s\}^{n}\right)$ for each $t \geq 0$ and for fixed $n \geq 1$. If $\left(Y_{1}, Y_{2}, \ldots, Y_{\alpha}\right)$ is a random vector obtained by $G_{d}$-transformation of the vector $\left(X_{1}, X_{2}, \ldots, X_{\alpha}\right)$, then all probabilities in the distribution of the vectors $\left(Y_{t+1}, Y_{t+2}, \ldots \ldots, Y_{t+m}\right)$ are upper bounded by $\frac{1}{s^{n+d}}$ for each $m>n+d$ and each $t \geq 0$.

Proof We have

$$
\begin{aligned}
& P\left\{Y_{t+1}=y_{t+1}, \ldots, Y_{n+d}=y_{n+d}, Y_{n+d+1}=y_{n+d+1}, \ldots, Y_{t+m}=y_{t+m}\right\} \\
& =P\left\{Y_{t+1}=y_{t+1}, \ldots, Y_{n+d}=y_{n+d}\right\} \times \\
& \quad \times P\left\{Y_{n+d+1}=y_{n+d+1}, \ldots, Y_{t+m}=y_{t+m} \mid Y_{t+1}=y_{t+1}, \ldots, Y_{n+d}=y_{n+d}\right\}
\end{aligned}
$$

By Theorem 2, for $m=n+d$, we have $P\left\{Y_{t+1}=y_{t+1}, \ldots, Y_{n+d}=y_{n+d}\right\}=$ $1 / s^{n+d}$. On the other hand, $P\left\{Y_{n+d+1}=y_{n+d+1}, \ldots, Y_{t+m}=y_{t+m} \mid Y_{t+1}=\right.$ $\left.y_{t+1}, \ldots, Y_{n+d}=y_{n+d}\right\} \leq 1$.

The transformation $G_{d}$ is not the unique possible generalization of the $E$-transformation. We can change the way of application of the quasigroup operation $*$ and we can obtain several other kind of transformations. As an example, for $d=3$ we can use the following applications of the operation $*$ (altogether, there are 120 different forms):

$Y_{4}=Y_{1} *\left(Y_{2} *\left(Y_{3} * X_{4}\right)\right)$ - this was used for definition of $G_{3}$ as in (5);

$Y_{4}=Y_{1} *\left(Y_{3} *\left(Y_{2} * X_{4}\right)\right) ; \quad Y_{4}=Y_{2} *\left(Y_{1} *\left(Y_{3} * X_{4}\right)\right) ;$

$Y_{4}=Y_{2} *\left(Y_{3} *\left(Y_{1} * X_{4}\right)\right) ; \quad Y_{4}=Y_{3} *\left(Y_{1} *\left(Y_{2} * X_{4}\right)\right) ;$

$Y_{4}=Y_{1} *\left(Y_{2} *\left(X_{4} * Y_{3}\right)\right) ; \quad Y_{4}=Y_{1} *\left(Y_{3} *\left(X_{4} * Y_{2}\right)\right) ; \quad$ and so on. 
For arbitrary $d$, we can choose any bracketing and we can place the variables $Y_{1}, \ldots, Y_{d}$ and $X_{d+1}$ in arbitrary order. By using the obtained form we can define a transformation $T: A^{+} \rightarrow A^{+}$in the same way as (5). Then we can state and proof theorems like Theorem 2 and Theorem 3; namely, as one can notice, the proof of Theorem 2 depends strongly on the possibilities a quasigroup equation with one unknown to be solved.

\section{EXPERIMENTAL RESULTS}

We made many experiments in order to check our theoretical results. Here we give an example. We have randomly chosen a string with $1,000,000$ letters of the alphabet $A=\{1,2,3,4\}$ with only letters uniformly distributed. A $G_{d}$ transformation was defined by using the quasigroup (6).

\begin{tabular}{l|llll}
$*$ & 1 & 2 & 3 & 4 \\
\hline 1 & 2 & 1 & 3 & 4 \\
2 & 3 & 4 & 2 & 1 \\
3 & 1 & 3 & 4 & 2 \\
4 & 4 & 2 & 1 & 3
\end{tabular}

We took leaders $l_{0}=1, l_{1}=1, \ldots, l_{d}=1$.

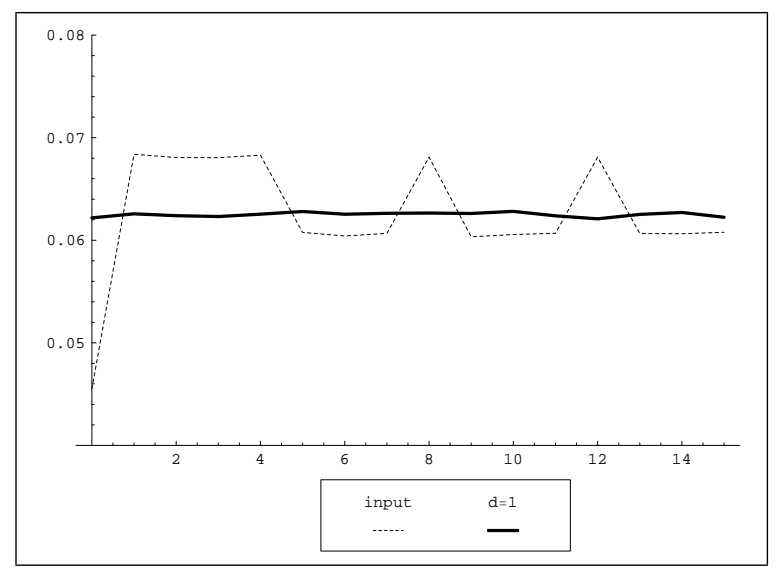

Figure 1. The distribution of the pairs in the input message and the output message for $d=1$

Прилози, Одд. мат. тех. науки, XXVII-XXVIII, 1-2 (2006-2007), стр. 41-53 


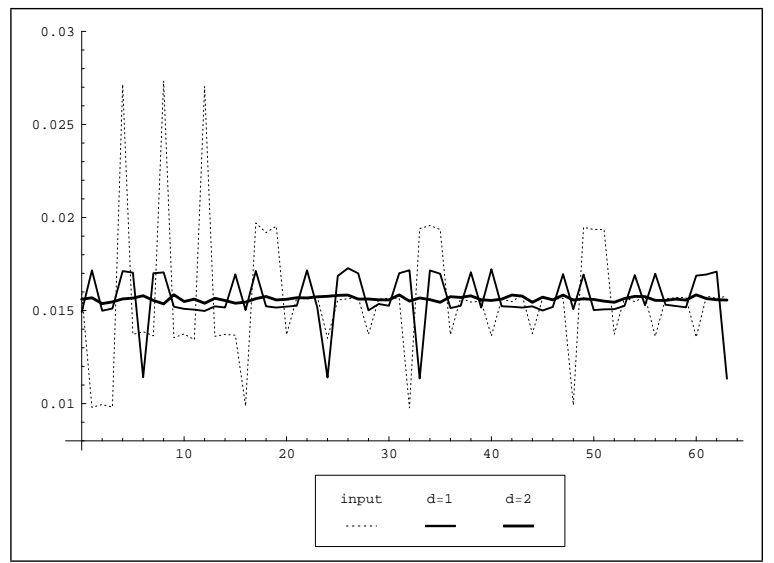

Figure 2. The distribution of the triplets in input message and output messages for $d=1$ and $d=2$

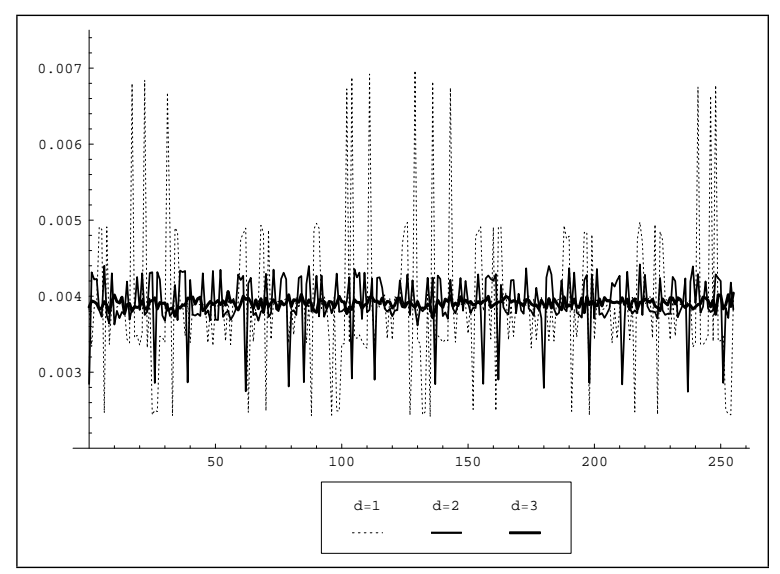

Figure 3. The distribution of the 4-tuples in output messages strings for $d=1$, $d=2$ and $d=3$ 
The distributions of pairs in the input message and output message for $d=1$ are presented on the Figure 1. The distributions of triplets in input message and output messages for $d=1,2$ are presented on the Figure 2 and the distributions of 4 -tuples for $d=1,2,3$ are presented on the Figure 3.

We can see on Figure 1 that, for $d=1$, the pairs are uniformly distributed. Also, we can see on Figure 2 that the distribution of the triplets for $d=1$ is closer to the uniform distribution than the distribution of triplets in the input message (which is in correlation with Theorem 3). The same is true for the 4-tuples (Figure 3).

\section{CONCLUSION}

We show in this paper that quasigroup transformations can be applied for improving the uniformly distributed strings, in the sense that from strings with uniformly distributed $n$-tuples it can be obtained strings with uniformly distributed $n+d$-tuples $(d \geq 1)$. The results can be applied in cryptography and coding theory for:

- improving the existing and defining new kinds of pseudo random number (and sequence) generators [11];

- defining primitives for hash functions [8], [9];

- defining primitives for stream cipher [7];

- design of random codes [10];

and many others.

\section{REFERENCES}

[1] Belousov, V.D.: Osnovi teorii kvazigrup i lup (The fundament of the theory of quasigroups and loops), (1967) "Nauka", Moskva.

[2] Denes, J., Keedwell, A.D.: Latin Squares and their Applications (1974) "The English Universities Press Ltd", Budapest.

[3] Markovski, S., Gligoroski, D., Andova, S.: Using quasigroups for oneone secure encoding., Proc. VIII Conf. Logic and Computer Science "LIRA '97", Novi Sad, (1997) 157-162.

Прилози, Одд. мат. тех. науки, XXVII-XXVIII, 1-2 (2006-2007), стр. 41-53 
[4] Markovski,S., Gligoroski,D., Bakeva,V.: Quasigrouop string processing: Part 1, Contributions, Sec. Math. Tech. Sci., MANU, XX 1-2 (1999) $13-28$.

[5] Markovski, S., Kusakatov, V.: Quasigroup String Processing: Part 2, Contributions, Sec. Math. Tech.Sci., MANU, XXI, 1-2 (2000) 15-32.

[6] Markovski, S., Kusakatov, V.: Quasigroup String Processing: Part 3, Contributions, Sec. Math. Tech.Sci., MANU, XXIII-XXIV, 1-2 (20022003), 7-27.

[7] Markovski, S.: Quasigroup string processing and applications in cryptography, First Intern. Conf. Mathematics and Informatics for Industry, Thessaloniki, Greece (2003), 278-289.

[8] Gligoroski, D., Markovski, S. and Bakeva, V.: On infinite class of strongly collision resistant $h A$ sh functions ' $E d o n-F$ ' with variable length of output, First Intern. Conf. Mathematics and Informatics for Industry, Thessaloniki, Greece (2003), 302-308.

[9] Markovski, S., Gligoroski, D., and Bakeva, V.: Quasigroup and Hash Functions, Disc. Math. and Appl, Sl.Shtrakov and K. Denecke ed., Proceedings of the 6th ICDMA, Bansko (2001), 43-50.

[10] Gligoroski, D., Markovski, S., Kocarev, Lj.: New Directions in Coding: From Statistical Physics to Quasigroup String Transformations, 2004 Inter. Symp. on Nonlinear Theor. and its Applic (NOLTA2004), Fukuoka, Japan, Nov.29 - Dec. 3, 2004, 545-548.

[11] Markovski, S., Gligoroski, D., Kocarev, Lj.: Unbiased Random Sequences from Quaisgroup String Transformations, H. Gilbert and H. Handschuh (Eds.): FSE 2005, LNCS 3557 (2005), 163-180. 


$$
\mathrm{P} \text { е } з \text { и м е }
$$

\section{КВАЗИГРУПНИ ТРАНСФОРМАЦИИ НА НИЗИ: ДЕЛ 4}

За дадена азбука $A$ и квазигрупна трансформација $*$ на множеството $A$, во наш претходен труд, е дефинирана квазигрупна трансформација $E: A^{+} \rightarrow A^{+}$, каде $A^{+}$е множеството од сите непразни конечни низи над $A$. Во овој труд, се дадени неколку генерализации на $E$ и се разгледуваат условите при кои трансформираните низи имаат рамномерна распределба на $n$-торки од букви од $A$. Добиените резултати може да се применат во криптографија, теорија на кодирање, дефинирање и подобрување на генератори на псевдо-случајни броеви итн.

Клучни зборови: квазигрупа, квазигрупна трансформација на низи, рамномерна распределба

Address:

\section{Smile Markovski}

Faculty of Natural Sciences and Mathematics, Institute of Informatics, Ss Cyril and Methodius University, Skopje

P. O. Box 162, MK-1001 Skopje, Republic of Macedonia smile@ii.edu.mk

\section{Verica Bakeva}

Faculty of Natural Sciences and Mathematics, Institute of Informatics, Ss Cyril and Methodius University, Skopje

P. O. Box 162, MK-1001 Skopje, Republic of Macedonia verica@ii.edu.mk 